\title{
Unexpected Reason Code
}

National Cancer Institute

\section{Source}

National Cancer Institute. Unexpected Reason Code. NCI Thesaurus. Code C93700.

A coded value specifying the rationale for why an unanticipated activity or event occurred. 